\author{
Cadernos de \\ ESTUDOS LINGUÍSTIICOS - (58.3), Campinas, pp. 445-460 - set./dez. 2016
}

\title{
SOCIOLINGUÍSTICA NO/DO BRASIL
}

\author{
RAQUEL MEISTER KO. FREITAG ${ }^{1}$
}

RESUMO: A Sociolinguística de orientação variacionista é uma das áreas de pesquisa mais abrangentes e produtivas no Brasil e segue um modo de trabalho muito particular, que se distancia da abordagem proposta por William Labov em "The Social Stratification of English in New York City". O texto retoma uma das duas obras pioneiras, "The Social Stratification of English in New York City" e "Language in the Inner City”, para então apresentar uma versão da Sociolinguística do Brasil e prospectar seus rumos, evidenciando a tensão entre o ativismo sociolinguístico e a documentação sociolinguística.

Palavras-chave: Ativismo sociolinguístico, documentação sociolinguística, Sociolinguística variacionista.

ABSTRACT: The variationist approach of Sociolinguistics is one of the largest and most productive linguistic research fields in Brazil, where it follows a very particular operational arrangement which distances itself from William Labov's approach in "The Social Stratification of English in New York City". This article recovers two of his seminal works, "The Social Stratification of English in New York City" and "Language in the inner city", in order to discuss Sociolinguistics in Brazil and the paths it takes. In so doing, this article highlights the tension between sociolinguistic activism and sociolinguistic documentation.

Keywords: Sociolinguistic activism, sociolinguistic documentation, Variationist sociolinguistics.

\section{INTRODUÇÃO}

A Sociolinguística de orientação variacionista é uma das áreas de pesquisa mais abrangentes e produtivas no Brasil.2 Sua "inauguração”, segundo Scherre e Roncarati (2008), se deu com a reorientação, a pedido de alguns alunos, de uma disciplina sobre contatos linguísticos a ser ministrada por Anthony Julius Naro no curso de mestrado da PUC-RJ para tratar do tema, em 1976, dez anos depois de publicado "The Social Stratification of English in New York City".

${ }^{1}$ Universidade Federal de Sergipe.

${ }^{2}$ Não há uma medida exata ou comparação possível para essa afirmação. No entanto, algumas evidências podem ser consideradas, como o fato de o GT de Sociolinguística ser um dos 21 GTs pioneiros da Anpoll, criados em 1985, e que até hoje mantém sua expressividade, com grande número de membros participantes. Além disso, Salomão (2011) apresenta um levantamento de 48 grupos de pesquisa ligados à sociolinguística de orientação variacionista registrados no diretório de grupos de pesquisa do CNPq. 
Apesar de o Brasil ter ingressado neste campo de estudos relativamente cedo, somente em 2006 tivemos a primeira tradução de uma obra de William Labov para o português, "Fundamentos empíricos para uma teoria de mudança linguística", e, em 2008, "Padrões Sociolinguísticos". "The Social Stratification of English in New York City" ainda continua sem tradução para o português, uma das prováveis razões para o fato de ser um texto pouco conhecido no cenário brasileiro, ou, ainda, conhecido por vias indiretas. O pouco conhecimento da obra, em especial dos aspectos metodológicos, talvez possa ser uma explicação para o que aqui se vai chamar de uma "Sociolinguística do Brasil". Para chegar à Sociolinguística do Brasil, vou fazer antes dois movimentos no texto: primeiro, apresentar, ainda que brevemente, duas obras de William Labov, "The Social Stratification of English in New York City" e "Language in the Inner City", enfocando seus princípios norteadores; no segundo momento, traçar uma versão da história da Sociolinguística no Brasil, para, por fim, discorrer sobre: a) a Sociolinguística do Brasil, e b) seus rumos, a partir do ponto de vista da tensão entre o ativismo sociolinguístico e a documentação sociolinguística.

\section{UM OLHAR SOBRE "THE SOCIAL STRATIFICATION OF ENGLISH IN NEW YORK CITY” E “LANGUAGE IN THE INNER CITY”}

Muitos aspectos de "The Social Stratification of English in New York City" são explorados em "Padrões Sociolinguísticos", alguns quase na íntegra, como o capítulo sobre a estratificação social do /r/ em lojas de departamento em Nova Iorque, além das discussões teórico-metodológicas acerca da dimensão estilística da variação. Esta apresentação vai retomar, então, os aspectos metodológicos relativos à coleta de dados.

O objetivo do estudo é observar uma correlação entre estratificação social e língua em Nova Iorque, cidade americana constituída por diferentes fluxos migratórios e com alta segmentação social que se manifesta inclusive linguisticamente, com estudos prévios desde 1896, como sobre o brooklynese - a fala dos nativos do Brooklyn, um distrito da cidade de Nova Iorque.

A partir de entrevistas exploratórias no Lower East Side, um bairro predominantemente de imigrantes e operários, residentes em tenements - prédios residenciais multifamiliares, antigos e degradados fisicamente -, Labov faz o delineamento das variáveis, considerando que certos traços do sistema linguístico parecem dar pistas sobre a categorização social do falante: /r/, /aeh/, /oh/, /th/, /dh/. A partir do levantamento destas variáveis linguísticas nas entrevistas exploratórias (assistemáticas), o estudo foi delineado de modo a considerar os efeitos sociais e estilísticos que poderiam condicionar o uso de cada uma delas. Para o controle dos efeitos estilísticos (definidos com base em níveis de atenção à fala - de mais cuidada a espontânea), foram considerados contextos de fala, como palavras em pares mínimos (especialmente para as vogais), leitura, a situação de entrevista sociolinguística. A análise das entrevistas exploratórias se deu com o controle da ocorrência das variáveis nos diferentes estilos de fala, com tratamento individual 446 
Cadernos de ESTUDOS LINGUífTICOS (58.3) - set./dez. 2016

(quantas vezes ocorreu cada variante das variáveis nos diferentes estilos de fala de cada informante). Os resultados deram pistas do grau de monitoramento estilístico de cada variável. Os efeitos dos fatores sociais na realização do /r/ nas lojas de departamento em Nova Iorque foram aferidos a partir de uma amostra constituída por uma coleta de dados rápida e anônima. Realizada pelo próprio Labov, nas lojas de departamento selecionadas em função da estratificação social de SEU público (Saks, Macy's e S. Klein) consistiu em abordar os funcionários, simulando uma situação de consulta sobre onde ficava determinado setor da loja, cuja resposta seria fourth floor, com uma pergunta para confirmar a resposta: Labov: "Onde fica o setor de vestidos de festa?”; Funcionário "quarto andar (fourth floor)”; Labov: “Onde?”; Funcionário: “Quarto andar”.

Após a abordagem, Labov anotava os dados produzidos pelo funcionário (dois ambientes linguísticos em final de sílaba - meio e final de palavra - e em dois estilos - informal e cuidado, na repetição) e atribuía um perfil social a partir da sua impressão. Não havia contato além da abordagem da interação, por isso, uma coleta rápida (quase instantânea, se comparada à entrevista sociolinguística, com cerca de uma hora de duração) e anônima (sem vínculo com o informante), de oitiva e impressionística. A partir destes dados, Labov pode estipular um perfil social e estilístico para a realização do /r/.

Aferidos efeitos sociais e estilísticos, dá-se o estudo no Lower East Side (ver Figura 1). A escolha deste bairro se deve ao fato de, à época, haver representação dos diferentes grupos étnicos (diferentemente dos guetos no Harlem e em Bed-Stuy, por exemplo): italianos, judeus, alemães, ucranianos, poloneses, afro-americanos, porto riquenhos, protestantes, entre outros. A seleção da área geográfica também se deu por conta de atuação conjunta com o projeto Mobilization for Youth (MFY), uma ação de larga escala sobre delinquência juvenil coordenada pela Universidade de Columbia. No bairro, foram mapeadas 33.932 unidades habitacionais (onde era possível encontrar informantes) que foram divididas em 250 lotes de 133 unidades. Em cada lote, foram escolhidas 5 casas aleatoriamente. No total, participariam 1.250 famílias e 40 entrevistadores. O número real atingido foi de 988 entrevistas (79\% da meta estipulada para esta coleta). ${ }^{3}$ Cada entrevista durava de 2 a 4 horas. Entretanto, esta ainda não era a coleta de dados. A American Language Survey (ALS), com a entrevista sociolinguística propriamente dita, foi realizada a partir dos informantes da MFY, de cujas 988 entrevistas, 280 eram porto-riquenhos e de outras origens étnica, totalizando 617 informantes (afro-americanos, judeus ortodoxos, judeus conservadores ou reformistas, católicos e protestantes). Com a exclusão dos nãonativos ou dos que chegaram à cidade depois dos 8 anos de idade, ficaram 312 informantes. Entre a coleta da MFY (junho de 1961) e a da ALS (junho de 1963), oito morreram e 109 se mudaram. Restaram 195 informantes. Por critérios de composição amostral, ficaram 158 informantes. Enfim, foram recontatados 122 informantes da MFY, que concederam as entrevistas sociolinguísticas, das

${ }^{3} \mathrm{O}$ censo populacional estimava cerca de 7.781 .984 habitantes para a cidade de Nova Iorque na década de 1960. 
quais 102 foram realizadas por William Labov e 20 por Michael Kac. Foram realizadas, ainda, 33 entrevistas curtas, chamadas de television interview (31 por Labov e 2 por Kac). Além das bases fundantes para a abordagem da variação sociolinguística (em duas perspectivas: a) tomar várias amostras da população e determinar o valor social da variável para cada grupo, o tipo de fala que é esperada para determinado grupo; ou b) determinar o padrão de distribuição da variável e identificar as características sociais de quem fala daquele jeito, de que grupo esperamos este tipo de modo de falar), a maior lição que fica desse estudo, além da diversidade e do rigor metodológico, é "conheça seus próprios dados”; em toda sua carreira, William Labov realizou pessoalmente 1000 entrevistas sociolinguísticas (LABOV 2016). A intuição de analista é intimamente ligada à sensibilidade de pesquisador de campo.

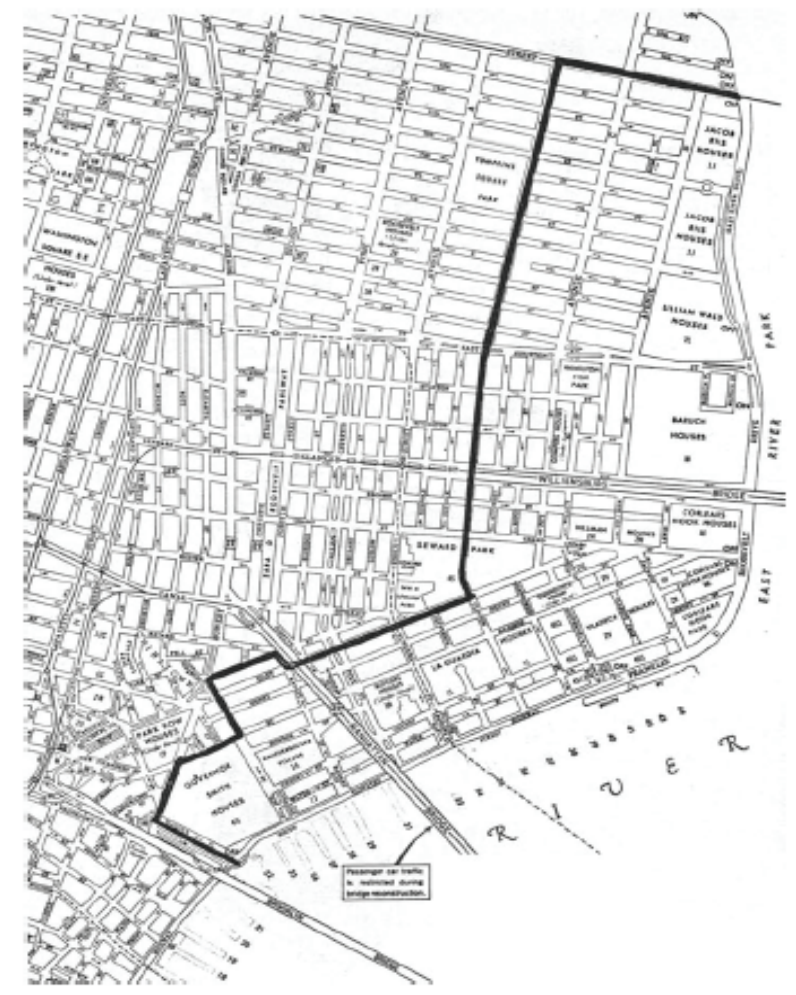

Figura 1: Mapa da região de Nova Iorque onde os dados foram coletados (Fonte: LABOV 2006 [1966]:103)

"Language in the Inner City" (1972) é outra obra cujos resultados são retomados em "Padrões sociolinguísticos", mas sempre com o viés de contribuição à teoria da variação e mudança. Um dos aspectos mais importantes dessa obra está no seu caráter educacional. Soares (1994), por exemplo, retoma a abordagem de Labov como a ideologia da diferença linguística. 
Cadernos de ESTUDOS LINGUÍSTICOS (58.3) - set./dez. 2016

"Language in the Inner City" é resultado do desenvolvimento de dois projetos de pesquisa cujo objetivo era analisar problemas relacionados à leitura e suas implicações teóricas. Falhas na proficiência em leitura eram óbvias nas escolas de Nova Iorque; diferenças dialetais poderiam ser sua causa? Para responder à questão, era preciso entender a língua, a cultura, a organização social e a situação política dos jovens negros na periferia das cidades americanas na década de 1960, e, mais especificamente, descrever o Black English Vernacular (BEV), hoje em dia chamado African American Vernacular English (AAVE), um dialeto regular e relativamente uniforme falado pela maioria dos jovens negros na maior parte dos Estados Unidos, especialmente na periferia das cidades como Nova Iorque, Boston, Detroit, Filadélfia, Washington, Cleveland, Chicago, St. Louis, São Francisco e Los Angeles (LABOV 1972:xiii). Labov explica que o rótulo BEV podia, à época, ser empregado para uma gama de falares de negros, como o Gullah, mas, no escopo do livro, BEV refere-se à língua falada por jovens entre 9 e 19 anos que estão envolvidos com a cultura de rua da periferia.

A equipe dos projetos envolvia quatro pesquisadores: William Labov e Paul Cohen, brancos, totalmente externos ao BEV, linguistas, e Clarence Robins e John Lewis, negros, conhecedores do BEV, não linguistas.

A principal conclusão do estudo é que a maior parte das causas das falhas na proficiência em leitura está nos conflitos políticos e culturais na sala de aula, para os quais as diferenças dialetais funcionam como símbolos. Além do ganho pedagógico, este trabalho trouxe à área contribuições metodológicas, na medida em que uma equipe mista, com pesquisadores envolvidos com a comunidade, permitiu o acesso a dados que não poderiam ser acessados por um pesquisador externo, reforçando a discussão sobre o paradoxo do observador. Houve ganhos no modelo de análise, já que os dados coletados serviram de base para o desenvolvimento de um modelo estatístico de regras variáveis (CEDERGREN; SANKOFF 1974), e houve ganhos para a teoria da variação e mudança, sistematizados nos capítulos 8 e 9 de "Padrões sociolinguísticos".

Em relação à metodologia desta pesquisa, estudos anteriores partiam de amostras de BEV coletadas em espaços institucionais, com adultos e efeitos da cultura da classe média. A proposta deste estudo tomou como informantes jovens do Harlem, uma região predominantemente negra na cidade de Nova Iorque. As abordagens iniciais constaram de entrevistas individuais com jovens de 10 a 12 anos em uma espécie de colônia de férias, com a replicação da técnica desenvolvida no Lower East Side. No entanto, o viés da seleção não favoreceu o acesso ao vernáculo, pois as entrevistas foram realizadas por Labov e Robins. Na observação participante de longo termo, o alvo foi o grupo de pré-adolescentes Thunderbirds: primeiramente, foram realizadas entrevistas com os líderes e depois sessões com os grupos, com microfones individuais e um microfone maior para captar o grupo todo. Com esta técnica, seria possível a observação das relações de liderança (por meio de tomadas de turno, ratificações, retificações). Foram incorporados à observação participante de longo termo os Aces, do prédio vizinho, e outro grupo no prédio dos Thunderbirds, os Oscar Brothers. À época, um novo pesquisador, John Lewis (“K.C."), um dos primeiros entrevistados, aderiu à equipe 
de pesquisadores, o que permitiu ampliar a coleta para contemplar Jets e Cobras, grupos hostis ums ao outro. Os Cobras eram membros do The Nation of Islam, tornaram-se vegetarianos e acreditavam que o mundo acabaria em 4 de julho de 1966. Os Jets eram hostis não só ao islã, mas a qualquer religião, e expandiram sua atuação para além de seu quarteirão. Para o estudo, foi constituída uma amostra de controle, com a realização de entrevistas com 100 adultos, moradores dos prédios dos Thunderbirds e da área dos Jets e dos Cobras, para comparar os usos: 20 adultos de classe média de apartamentos/casa de Lenox e Riverton; 40 adultos de classe trabalhadora da área dos Jets; 40 adultos de classe trabalhadora da área dos Cobras. Além disso, foram entrevistados dois grupos de adolescentes e pré-adolescentes brancos de upper-Manhattan, sem contato com a região dos negros, e sem contato com o BEV. Foi a partir desta amostra, constituída com rigor metodológico e com grupos de controle, que foram descritos os padrões de uso do $\mathrm{BEV}$, a partir dos quais poderiam ser especuladas as origens para os problemas de leitura dos falantes de BEV.

Basicamente, há dois problemas, opostos e complementares: o desconhecimento das regras do inglês padrão por parte dos falantes do inglês não padrão, e o desconhecimento das regras do inglês não padrão por parte dos professores e autores de textos. Estes problemas apareciam no sistema educacional sob a forma simplista de uma forte e inexplicável resistência por parte desse grupo de falantes em aprender as regras que a escola precisa ensinar, quando na verdade são resultados de conflitos entre a estrutura do inglês padrão e não padrão (interferências decorrentes da habilidade de aprendizagem e o descompasso com as estruturas linguísticas) e o funcionamento dessas variedades (interferências decorrentes do desejo de aprender o inglês padrão e o descompasso entre as funções do inglês padrão e não padrão em dada cultura).

Estas diferenças ficam mais evidentes com os testes de percepção realizados, em que os sujeitos ouviam séries de três palavras e precisavam distinguir se havia uma com significado diferente, especialmente com o segmento "-ed" em final de palavras: somente os Thunderbirds perceberam a diferença. Outro teste aplicado foi o de correção em sala de aula, que consistia em apresentar um enunciado do tipo: "Em uma lição de escola, estas formas estão corretas: He pick me ('Ele me escolheu'), I've pass my test ('Passei na prova'), Last week I kick Donald in the mouth so the teacher throwed me out the class ('Semana passada eu chutei a boca do Donald então o professor me expulsou da sala')?" O teste detectou baixa habilidade, tanto por parte dos Thunderbirds, quanto por parte dos Cobras, em perceber a falta do morfema. A baixa habilidade também é verificada em um teste de leitura, no qual a marcação do passado de read vem na realização da vogal como [i:] ou como [ $\varepsilon$ ] (Last month I read five books 'No mês passado li quatro livros', vs. Tim read all the time 'Tim lê o tempo todo').

As consequências de reconhecer o BEV no sistema educacional são que os professores de leitura precisam distinguir cada variante em relação ao inglês padrão na leitura oral como erro de leitura ou diferença de pronúncia. Professores nas séries iniciais devem estar prontos para aceitar a existência de diferentes conjuntos de homônimos na fala de crianças negras. Tal aceitação preserva a 450 
Cadernos de ESTUDOS LINGUífSTICOS (58.3) - set./dez. 2016

confiança da criança na sua fonotaxe e poderá facilitar seu aprendizado na leitura. Os treinos de percepção nos primeiros anos escolares merecem atenção especial, fazendo as crianças ouvir e realizar distinções entre inglês padrão e não padrão (LABOV 1972:34).

Por outro lado, pode-se dizer que a maior contribuição de "Language in the Inner City" é o chamamento ao ativismo sociolinguístico. Não estou me referindo ao movimento contra o preconceito linguístico - uma visão romântica e inocente de que as pessoas deixarão de ser preconceituosas, ou, na versão mais maléfica, simplesmente dizer que não está errado falar de um jeito ou de outro, sem apresentar, contudo, a oportunidade de perceber uma escala de valores, os mercados linguísticos nos termos de Bourdieu (1977); ${ }^{4}$ refiro-me, sim, a uma postura ativa dos pesquisadores da Sociolinguística em mobilizar os resultados de seus estudos para revertê-los em tecnologia social: materiais didáticos e de difusão no suporte, reconhecimento e valorização das variedades.

Segundo Labov (1972:240-241), as falácias da teoria do déficit linguístico seriam tão óbvias que não vale a pena expô-las. ${ }^{5}$ Mesmo assim, é necessário expôlas e sua exposição é um importante trabalho a ser empreendido. Se linguistas puderem contribuir com seu conhecimento e com sua energia para esse fim, teremos feito um grande avanço para justificar o investimento em pesquisa básica que nos é dado em nosso campo de pesquisa.

Essa lição do ativismo sociolinguístico continua atual mesmo tanto tempo depois do estudo laboviano - pelo menos no Brasil, onde ainda vivemos os mesmos problemas. Apesar dos mais de 50 anos não só dos estudos sociolinguísticos, mas da pesquisa linguística no Brasil, suas contribuições ainda não chegam ao ensino de língua materna, em que tendências pedagógicas negligenciam a importância do nível estrutural, assim como o desenvolvimento de habilidades de percepção e de escuta.

${ }^{4}$ Em determinados mercados linguísticos, quando certas pessoas falam (ou escrevem) são respeitadas, acreditadas, apreciadas, obedecidas. Quando, porém, outras pessoas falam, seu discurso não obtém o mesmo crédito, o mesmo valor.

${ }^{5}$ Segundo Labov (1972), as respostas verbais de crianças de classe baixa a uma situação formal e ameaçadora é usada para mostrar sua falta de capacidade ou déficit verbal, declarado como sendo a maior causa do baixo desempenho escolar das crianças de classe baixa. Ainda que crianças da classe média tenham desempenho melhor na escola, os seus hábitos de fala são vistos como necessários para aprendizagem. Diferenças de classe e diferenças étnicas nas formas gramaticais são igualadas a diferenças na capacidade de análise lógica. Ensinar a criança, por imitação de certos padrões de fala formal da classe média é visto como ensiná-la a pensar logicamente. As crianças que aprendem esses padrões formais são aquelas que pensam logicamente e por hipótese têm um desempenho melhor em leitura e aritmética nos anos seguintes. Linguistas concordam que variedades não padrão são altamente estruturadas, ou seja, essas variedades não são um conjunto de erros causados pela falha de seus falantes em dominar o inglês padrão. Quando linguistas dizem que o BEV é um sistema, eles querem dizer que ele difere de outras variedades porque tem recursos gramaticais regulares e regidos por regras, então são meios equivalentes de expressar o mesmo conteúdo lógico. 
Do modo como está direcionada, a revisão acima das obras de Labov ajuda a entender como a Sociolinguística chegou ao Brasil.

\section{SOCIOLINGUÍSTICA NO/DO BRASIL}

O Movimento Brasileiro de Alfabetização (Mobral) foi instituído pela Lei $\mathrm{n}^{\circ} 5.379$, de 15 de dezembro de 1967 , com o objetivo de atender à alfabetização funcional de jovens e adultos, que abandonaram a escola, visando a conduzir a pessoa a adquirir a habilidade da leitura, da escrita e do cálculo como meio de integrá-la à sua comunidade, permitindo melhores condições de vida na sociedade. Pelo planejamento do programa, o analfabetismo estaria erradicado no país até o final da década de 1970 (pelo menos na faixa até 35 anos de idade). O programa foi encerrado em 1985, mas a alfabetização desse segmento populacional ficou a cargo do Projeto Fundação Educar (1985 a 1990), sendo substituído em 1990 pelo Plano Nacional de Alfabetização e Cidadania e, a partir de 1991, pela Educação de Jovens e Adultos, uma modalidade de ensino (OLIVEIRA 1989; SAVIANI 2008).

Não é um propósito aqui entrar na discussão político-ideológica sobre o Mobral, mas sim entender o seu contexto na sua relação com a sociolinguística. Entre 1969 e 1974, o programa foi presidido por Mario Henrique Simonsen, economista e banqueiro, momento em que o programa se aproximou ainda mais aos interesses do capital, com o fomento da Fundação Ford, que financiou o projeto Competências Básicas do Português (1977). Segundo relata Anthony Naro, em entrevista a Sebastião Votre, Claudia Roncarati e Rebeca Nascimento (2008), Miriam Lemle o procurou para articularem a proposta sob encomenda do Mobral que tinha que cumprir dois requisitos: ser pesquisa e ter o uso do computador. Naro disse que sabia o que fazer, pois tinha assistido anteriormente a uma palestra de Labov, em Chicago; entrou então em contato com ele, que indicou Gregory Guy, que veio ao Brasil realizar coleta de dados e trazer os programas computacionais para o projeto. E assim a sociolinguística variacionista se torna uma linha de pesquisa no Brasil. Não foi algo planejado; foi, segundo Naro, um "conjunto de circunstâncias" (e interesses) que levou a este empreendimento.

A sociolinguística do Brasil se caracteriza por sua operacionalização em bancos de dados linguísticos. São amostras sistematizadas de língua, coletadas em um universo definido como comunidade de fala. O que mantem da sociolinguística pioneira de "The Social Stratification of English in New York City" é o fato de seguir uma estratificação de acordo com critérios sociodemográficos amplos coletadas pelo protocolo de entrevista sociolinguística.

Originalmente como Projeto Censo da Variação Linguística do Estado do Rio de Janeiro, o Programa de Estudos sobre o Uso da Língua - Peul, sob coordenação de Anthony Naro, foi o pioneiro na adoção desses aspectos da metodologia da Sociolinguística Variacionista no Brasil, com o objetivo de estudar o português falado no Rio de Janeiro. 
Cadernos de ESTUDOS LINGUUISTICOS (58.3) - set./dez. 2016

Inicialmente, o projeto previa um total de 600 horas de gravação (considerando-se uma hora por informante), mas a amostra Censo 1980 realizou gravação com apenas 64 informantes, dos quais 16 foram recontatados na amostra Censo 2000, quando outras 32 entrevistas foram realizadas. Considere-se que estas amostras recobrem toda a cidade do Rio de Janeiro, em duas fatias temporais, enquanto a metodologia laboviana realizou mais entrevistas, em uma mesma fatia temporal, circunscritas a uma área geográfica bem definida, tal como mostra a Figura 1 acima.

Outros bancos de dados (socio)linguísticos do Brasil - a exemplo do projeto Variação Linguística Urbana da Região Sul do Brasil (Varsul), o primeiro a replicar o modelo do Peul -, seguem as mesmas diretrizes: são baseados em comunidades de fala, com seleção dita "aleatória" de informantes que tenham nascido na comunidade, onde tenham vivido pelo menos 2/3 de suas vidas, filhos de pais com as mesmas características e reconhecidos pelos pares como membros da comunidade de fala (FREITAG; MARTINS; TAVARES 2012). A amostra é estratificada em função de características sociodemográficas (sexo, idade, escolaridade, zona de residência etc.), formando, a partir da confluência das características sociodemográficas, células sociais, sempre ortogonais (a mesma quantidade de informantes por célula).

A finalidade do Projeto Censo da Variação Linguística do Estado do Rio de Janeiro era a busca da norma urbana não culta do português falado no Brasil, já que a norma culta era objeto do projeto Norma Urbana Culta - NURC, que, embora não tenha seguido a orientação metodológica da sociolinguística variacionista, possibilita o controle de aspectos estilísticos (diferentes tipos de coleta em função da atenção à fala, como as elocuções formais, o diálogo entre entrevistador e informante e o diálogo entre informantes) e sociais/dialetais (foram realizadas coletas em seis capitais: Porto Alegre, São Paulo, Rio de Janeiro, Salvador, Recife e Fortaleza) (CALLOU 1999). A abordagem a partir de bancos de dados sociolinguísticos trouxe subsídios para a descrição do português brasileiro, com a padronização da amostragem e coleta de dados, que permite, de certa forma, a comparação de resultados, e, assim, traz contribuições para uma norma brasileira, com descrições sociolinguísticas em interface teórica tanto com abordagens formais (como sociolinguística paramétrica, gramáticas em competição), como com abordagens funcionais (sociofuncionalismo, gramaticalização) (FREITAG 2009).

Por que a sociolinguística do Brasil tomou esse rumo, com a priorização das interfaces teóricas em detrimento aos papéis sociais, com coletas de dados com número relativamente reduzidos de informantes por comunidade de fala? A interação entre dois fatores - produção de dados para alimentar modelos teóricos de língua e a força de políticas de financiamento e nucleação da pesquisa na pós-graduação - pode dar pistas para esse caminho que a Sociolinguística do Brasil seguiu. 
No Brasil, a pesquisa é uma atividade que está diretamente ligada à pósgraduação, majoritariamente nas instituições públicas de ensino superior. A década de 1970 viu um salto no número de programas de pós-graduação no Brasil: em 1965, eram 27 programas de mestrado e 11 de doutorado; em 1975, eram 429 programas de mestrado e 149 de doutorado (BALBACHEVSKY 2005). Apesar do aumento no número de programas, não necessariamente houve a nucleação de pesquisadores alinhados à mesma teoria; a necessidade de trabalho em linhas de pesquisa requer ou um grupo alinhado em torno de uma teoria, ou um grupo alinhado a um objeto, com interfaces e aproximações teóricas. Isso implica, ainda, nas políticas de financiamento a projetos: têm prioridade aqueles que atendam um volume maior de pesquisadores e que tenham poder explanatório mais amplo. ${ }^{6}$ O Peul, em sua formulação de 1987, reunia pesquisadores que tinham em comum o fato de "trabalhar com a língua em uso, de pensar questões gerais de variação e mudança linguística e de não trabalhar com dados produzidos pela intuição" (SCHERRE; RONCARATI 2008: 39). Já no caso do Varsul, por sua vez, os objetivos são: “a) subsídios para a descrição do português falado no País; b) condições para teste e desenvolvimento de teorias linguísticas; c) condições para a formação de novos pesquisadores; d) subsídios para programas educacionais, promovendo o conhecimento e o respeito às variedades linguísticas." (BISOL; MENON; TASCA 2008: 50-51, grifos acrescidos). Deste direcionamento deriva o fato de que, em muitos trabalhos que utilizam bancos de dados sociolinguísticos no Brasil, a Sociolinguística é tomada como uma metodologia, e não como uma teoria, com poder explanatório per se. Essa visão é apregoada pelo pioneiro do modelo no Brasil; Naro afirma:

\begin{abstract}
A Sociolinguística é sobretudo linguística. A Teoria da Variação é uma metodologia. Tem que ter por detrás uma teoria linguística. [...] a Sociolinguística é essa: o que ela faz é estudar a gramática em ação. Mas ela tem que ter uma teoria da gramática por detrás, para orientar as grandes perguntas. Também existe um ramo da Sociolinguística mais voltado para a Sociologia. Mas, pelo menos até agora [2008], no Brasil, ninguém se interessou por ele [...] É, por exemplo, no papel das mulheres e dos homens na sociedade ou em um grupo qualquer. Lá nos Estados Unidos, o foco era principalmente nos afro-americanos. Mas existe todo um ramo da Sociolinguística mais voltado para questões sociais do que para questões linguísticas... Mas, aqui no Brasil, não temos esse campo de estudos. (VOTRE \& RONCARATI 2008:14)
\end{abstract}

${ }^{6}$ Scherre e Roncarati (2008) relatam que as amostras do Peul foram constituídas com financiamento de diferentes agências, em diferentes etapas, como a Financiadora de Projetos - Finep, e o Instituto de Pesquisas Educacionais Anísio Teixeira - Inep. A Finep também financiou outros projetos que visavam à constituição de bancos de dados sociolinguísticos, como o Dialetos Sociais Cearenses e o Varsul. No cenário brasileiro de fomento à pesquisa, a Finep financia projetos necessariamente coletivos, com abrangência mais ampla. Como a coleta de dados é uma atividade dispendiosa, tanto de tempo como de recursos financeiros, pode-se dizer que a Finep, ao financiar projetos de natureza coletiva, ajudou a dar o formato da Sociolinguística do Brasil. 
Cadernos de EsTUDOS LINGUísticos (58.3) - set./dez. 2016

Há que se considerar também que, embora seja rotulada como "teoria", Labov, em estudos posteriores, considera o modelo enquanto campo científico não como "teoria de língua", mas como um "poderoso método de provas procedentes de estudos quantitativos" (LABOV 1978:1). Talvez essa seja uma explicação para o fato das obras traduzidas para o português serem as que tratam dos aspectos fundantes da teoria-metodologia, e não as que apresentam seus resultados sociais, como "The Social Stratification of English in New York City" e "Language in the Inner City".

Por outro lado, o encobrimento desta Sociolinguística mais voltada para as questões sociais pode ser consequência das questões impostas pela política de financiamento e de nucleação da pesquisa e pós-graduação no Brasil, com a priorização de um objeto mais amplo, o português falado no Brasil, a ser descrito por diferentes vieses teóricos para nuclear grupos de pesquisa, como é o caso do Peul e do Varsul, por exemplo, mas não apenas estes. Há diferenças socioculturais marcantes na realidade brasileira, quando em contraste com o que acontecia nos Estados Unidos à época, especialmente no que diz respeito ao preconceito. Enquanto nos Estados Unidos a segregação foi política oficial até meados da década de 1960, o Brasil vivia (e ainda vive) o "racismo cordial" (TURRA; VENTURINI 1995): um país onde as pessoas assumem posturas racistas, mas negam ser racistas e a questão do preconceito é escamoteada. As categorias sociodemográficas estratificadas nos bancos de dados sociolinguísticos brasileiros não contemplam raça/etnia, nem classe social - uma tentativa de controle foi feita no banco de dados BDS Pampa, mas não replicada (cf. AMARAL 2003) -, motes dos estudos pioneiros da sociolinguística variacionista norte-americana.

\section{RUMOS}

Ao optar por migrar de região do Brasil em função de oportunidade de trabalho (fui formada pela Universidade Federal de Santa Catarina e atuo profissionalmente na Universidade Federal de Sergipe), emergiu minha sensibilidade sociolinguística - até então adormecida e subjacente a uma formação teórica funcionalista de orientação norte-americana. Foi o contato com outra variedade do português que fez reavivar em mim a necessidade de repensar a metodologia, de modo a contemplar a dimensão social de modo mais condizente com a realidade atual. Por exemplo, os bancos de forma sociolinguísticos são classificados quanto a sexo, em termos binários. Por conta da estratificação dos bancos de dados, os estudos sociolinguísticos brasileiros que discutem o papel do gênero na linguagem o fazem a partir da identificação de informantes selecionados a partir do sexo. Tal cenário leva a resultados especulativos, especialmente em relação à mulher com a variedade de prestígio e o seu papel na mudança linguística (FREITAG 2015). 
Ainda em relação à metodologia, o controle da escolarização surgiu como uma alternativa indireta para o controle da classe social nas amostras sociolinguísticas brasileiras, como argumentam Rodrigues (2009), Freitag (2011), Mendes \& Oushiro (2012). Níveis de escolarização mais altos, como o grau universitário, seriam, por hipótese, uma forma de controle de pertencimento a classes sociais mais altas. Hoje, com a quase universalização da educação básica e crescimento exponencial na educação superior, é tarefa difícil preencher determinadas células sociais de bancos de dados sociolinguísticos, como a de um jovem analfabeto, mesmo fora dos grandes centros. Em grandes centros, encontrar um informante jovem que cursou apenas o fundamental menor é tarefa possivelmente ainda mais difícil.

O preenchimento de determinadas células sociais a fim de atender aos critérios básicos de seleção de informantes (que remontam à Dialetologia, como ter nascido e vivido na comunidade) tem se tornado cada vez mais difícil, especialmente em função dos fluxos migratórios e da mobilidade que caracterizam nossa época: ter nascido na comunidade e ser filho de pais igualmente nascidos na comunidade, sem nunca ter morado fora, são exigências muito difíceis de atender atualmente (FREITAG 2011). Isso faz com que, diferentemente do que é apregoado (e do que William Labov fez no estudo sobre a estratificação do inglês em Nova Iorque, com a coleta no Lower East Side), os bancos de dados não têm amostragem probabilística aleatória estratificada, mas sim uma amostra de cotas por conveniência e julgamento, na medida em que os indivíduos são selecionados pelo critério de disponibilidade e voluntariedade em aceitar os termos da coleta, especialmente as amostras que são chanceladas por comitê de ética. Estas práticas metodológicas requerem maior atenção antes de uma generalização de resultados, com reflexão sobre seu real poder explanatório, em termos sociais (o quão generalizável o resultado pode ser, a partir de uma amostra de conveniência, para toda uma comunidade de fala).

A trajetória de constituição de bancos de dados sociolinguísticos deve ser mantida, pois já temos uma série histórica que permite identificar tendências a partir da distribuição de resultados em função das categorias sociodemográficas de estratificação de amostras. Proponho chamar essa abordagem de documentação sociolinguística, um protocolo de orientação sociolinguística para a geração de dados para alimentar descrições linguísticas e testagem de teorias. Sob a égide da documentação sociolinguística, o próximo passo seria implementar a proposta de Gisele Machline Oliveira e Silva, de criar um “'Guarda-chuva nacional', formando grupos que organizassem a coleta e análise dos dados com metodologias e teorias semelhantes, de forma a possibilitar a comparação dos resultados obtidos, visando mapear semelhanças e diferenças linguísticas existentes no vasto território brasileiro" (SCHERRE; RONCARATI 2008:41).

Os próximos desafios a serem superados se referem ao investimento em diversidade metodológica, aos moldes dos estudos pioneiros (com testes de atitude, diferentes tipos de coleta e maior investimento em coletas de longo termo). A documentação sociolinguística requer uma equipe multidisciplinar. Neste momento, o que temos é uma Sociolinguística feita só por linguistas, o que releva o componente linguístico, mas o controle do social é feito por default dos bancos de dados. 
Entretanto, o mais importante é a busca pela inserção em políticas públicas (impacto social) da Sociolinguística do Brasil, o ativismo sociolinguístico. Para isso, é preciso investir em abordagens que enfatizam o lado social da sociolinguística, não só voltada para o campo educacional, mas também cultural. Por exemplo, temos o Inventário Nacional da Diversidade Linguística, iniciativa do Instituto do Patrimônio Histórico e Artístico Nacional - IPHAN, que se configura como uma política para a salvaguarda da diversidade linguística brasileira. Os conceitos de variedades dialetais da Língua Portuguesa, crioulos e línguas afro-brasileiras não são matéria pacífica, seja na literatura científica, com a discussão acerca dos traços linguísticos limítrofes entre variedades, crioulos e pidgins, seja no âmbito do Inventário Nacional da Diversidade Linguística, na medida em que as definições são baseadas em critérios populacionais ou de origem. A falta de clareza sobre qual critério é preponderante pode inviabilizar o processo de identificação de variedades, sendo assim necessária a proposição de ações que visem a clarificar esta distinção considerando não só a perspectiva linguística (descrição da língua), mas também as perspectivas etnográfica (como a comunidade percebe e se autoidentifica) e jurídica (por tratar-se de elemento constitutivo da diversidade linguística nacional e, portanto, um bem de natureza difusa). Dadas as condições sócio-históricas de formação do Brasil, a região Nordeste é profícua em contatos dos quais podem decorrer crioulos e línguas afro-brasileiras. A partir de experiências anteriores, que foram compartilhadas e discutidas no Workshop Metodologia de Coleta e Manipulação de Dados em Sociolinguística (FREITAG 2014), o projeto "Falares Sergipanos virtual: variedade, diversidade, contato e os direitos linguísticos" (MJ/CFDD 01/2015), em parceira com meus colegas da Universidade Federal de Sergipe, Ricardo Nascimento Abreu e Antonio Félix Souza Neto, propõe uma ação-piloto de documentação linguística do Estado de Sergipe, o menor em território no Brasil, a fim de testar a viabilidade de aplicação dos conceitos de variedades dialetais da Língua Portuguesa, crioulos e línguas afro-brasileiras, contribuindo também para o registro, salvaguarda e difusão da diversidade linguística no território sergipano.

É preciso, ainda, construir um senso de ativismo sociolinguístico, aos moldes do que William Labov preconiza em "Language in the Inner City”, no campo educacional, com a formação de professores não só sensíveis à pedagogia da variação linguística (que, apesar de amplamente difundida, ainda não sai dos meios acadêmicos; vide a polêmica do livro didático "Por uma vida melhor"7), mas capazes de implementar efetivamente em sala de aula um programa de ensino

\footnotetext{
${ }^{7}$ A exemplificação de usos variáveis quanto à concordância em situações de fala em um livro didático destinado à educação de jovens e adultos (RAMOS 2011) causou grande celeuma na sociedade brasileira com interpretações amplamente difundidas pela mídia de que o governo estava incentivando a falar errado. Respostas e análises acadêmicas podem ser conferidas em Lucchesi (2011), Scherre (2013), Baronas e Cox (2013), entre outros. Observe-se que o contexto de educação de jovens e adultos é muito próximo do Mobral, objeto de análise de Lemle e Naro (1977); embora as políticas educacionais tenham avançado - o tratamento da variação é um dos itens a serem contemplados pelos livros selecionados pelo Programa Nacional do Livro Didático, o episódio evidencia que, por mais que a área da sociolinguística seja produtiva em termos de pesquisa e documentação sociolinguística, não consegue ainda alcançar a sociedade, especificamente no que diz respeito ao reconhecimento das variedades; falta, ainda, um ativismo sociolinguístico.
} 
voltado à diversidade linguística. A diversidade linguística está presente nas políticas públicas, como nos documentos norteadores das diretrizes curriculares, como os Parâmetros Nacionais de Língua Portuguesa (PCN) e a Base Nacional Curricular Comum (BNCC), nos documentos norteadores da avaliação de materiais, como o edital do Programa Nacional do Livro Didático de Língua Portuguesa (PNLD), e nos programas de avaliação dos cursos de formação inicial, como no edital do Exame Nacional de Desempenho dos Estudantes (Enade). O grande gargalo, no entanto, é chegar à sala de aula. O Programa de Mestrado Profissional em Letras (Profletras), iniciado em 2013 e oferecido em rede a professores em regência de classe em turmas do ensino fundamental de escolas públicas, tem duas disciplinas obrigatórias específicas para o tratamento da variação linguística na sala de aula: "Fonologia, variação e ensino" e "Gramática, variação e ensino". No entanto, apesar das iniciativas advindas das políticas educacionais, ainda estamos engatinhando quanto ao ativismo sociolinguístico no campo da educação. O impacto educacional advindo da abordagem sociolinguística de orientação variacionista ainda não se faz presente na sociedade brasileira do mesmo modo como aconteceu nos Estados Unidos: Rickford (2016) destaca a importância dos estudos pioneiros de Labov para a educação, especialmente para a leitura, para os falantes de diferentes variedades vernaculares do inglês; em retrospectiva, ele evidencia o quanto esta abordagem aumentou as expectativas para a vida destes falantes, em geral minorizados do ponto de vista étnico-racial. Ainda nos falta muito para atingir este patamar no Brasil.

Enquanto, no cenário internacional, os 50 anos de "The Social Stratification of English in New York City" fomentam discussões relacionadas à coleta de dados com ênfase em aspectos etnográficos e a noção de comunidades de práticas (MEYERHOFF 2016), no Brasil, precisamos resgatar este lado mais social da sociolinguística, contemplando não só coletas que não sigam estratificações fechadas e homogeneizantes, mas que percebam a comunidade como um todo. Isso requer um engajamento maior com a comunidade e com o informante. Meyerhoff (2016) destaca que o próprio Labov, ao revisitar a coleta inicial do "The Social Stratification of English in New York City", recomenda mais do que um único encontro entre o entrevistador e o entrevistado, relevando a importância do trabalho articulado entre a pesquisa de ampla amostragem e a observação participante. Os encontros mais frequentes fazem com que o vernáculo emerja. Constatamos isso na coleta de dados da comunidade religiosa do povoado Açuzinho (FREITAG; SANTANA; ANDRADE 2014), em que o grupo foi acompanhado duas vezes por semana por seis meses, permitindo maior diversidade de situações quanto ao monitoramento da fala, ao ponto de que as documentadoras de campo fossem consideradas membros da própria comunidade.

Esta é a visão e estas são perspectivas de uma pesquisadora da terceira geração, formada pela escola da Sociolinguística do Brasil, mas que, ao sair da sua zona dialetal de conforto, teve que deixar de lado a validação da teoria linguística - sou especialista na interface sintaxe-semântica - com dados de fala e começou a se preocupar com questões de estilo e identidade. Foi uma mudança de foco do dado para o falante. Isso me fez estudar e mudar a metodologia de 
Cadernos de ESTUDOS LINGUÍSTICOS (58.3) - set./dez. 2016

coleta de dados na qual fui formada para contemplar estes aspectos. Talvez, nos próximos 50 anos, com as sementes plantadas neste momento de virada, a discussão de aspectos metodológicos possibilite fazer, também, Sociolinguística no Brasil com uma articulação mais efetiva entre a documentação e o ativismo sociolinguísticos.

\section{REFERÊNCIAS}

AMARAL, Luis Centeno. A concordância verbal de segunda pessoa do singular em Pelotas e suas implicações linguísticas e sociais. Tese (Doutorado em Letras) -Universidade Federal do Rio Grande do Sul, 2003.

BALBACHEVSKY, Elizabeth. A pós-graduação no Brasil: novos desafios para uma política bem sucedida. In: BROCK, Colin; SCHWARTZMAN, Simon. Os desafios da educação no Brasil. Rio de Janeiro: Nova Fronteira, 2005, p. 285-314.

BARONAS, Roberto Leiser; COX, Maria Inês Pagliarini. Por uma vida melhor na mídia: discurso, aforização e polêmica. Linguagem em (Dis)curso, n. 13, v. 1, p. 65-93, 2013.

BISOL, Leda; MENON, Odete Pereira da Silva; TASCA, Maria. VARSUL, um banco de dados. In: VOTRE, Sebastião; RONCARATI, Claudia (ed.). Anthony Julius Naro e a linguística no Brasil: uma homenagem acadêmica. Rio de Janeiro: 7Letras, 2008, p. 50-58.

BOURDIEU, Pierre. L'économie des échanges linguistiques. Langue française, n. 34, p. 17-34, 1977.

CALLOU, Dinah. O projeto NURC no Brasil: da década de 70 à década de 90. Lingüistica, n. 11, p. 231-50, 1999.

CEDERGREN, Henrietta J.; SANKOFF, David. Variable rules: Performance as a statistical reflection of competence. Language, p. 333-355, 1974.

FREITAG, Raquel Meister Ko. (Re)discutindo sexo/gênero na sociolinguística. In: FREITAG, Raquel Meister Ko.; SEVERO, Cristine Gorski (ed.). Mulheres, Linguagem e Poder - Estudos de Gênero na Sociolinguística Brasileira. São Paulo: Editora Edgard Blücher, 2015, p. 17-74.

FREITAG, Raquel Meister Ko. Metodologia de Coleta e Manipulação de Dados em Sociolinguística. São Paulo: Editora Edgard Blücher, 2014.

FREITAG, Raquel Meister Ko. O social da sociolinguística: o controle de fatores sociais. Diadorim, n. 8, v.1, p. 43-58, 2011.

FREITAG, Raquel Meister Ko. Problemas teórico-metodológicos para o estudo da variação linguística nos níveis gramaticais mais altos. Matraga, v. 16, n. 24, p. 115-132, 2009.

FREITAG, Raquel Meister Ko.; MARTINS, Marco Antonio; TAVARES, Maria Alice. Bancos de dados sociolinguísticos do português brasileiro e os estudos de terceira onda: potencialidades e limitações. Alfa: Revista de Linguística, v. 56, n. 3, p. 917-944, 2012.

FREITAG, Raquel Meister Ko; SANTANA, Cristiane Conceição; ANDRADE, Thaís Regina Conceição. Práticas constitutivas do povoado Açuzinho. Revista Ambivalências, v. 2, n. 3, p. 194-217, 2014.

LABOV, William. Afterword: Where are we now? Journal of Sociolinguistics, v. 20, n. 4, p. 581-602, 2016. 
FREITAG - Sociolinguística no/do Brasil

LABOV, William. Language in the Inner City: Studies in the Black English vernacular. Pennsylvania: University of Pennsylvania Press, 1972.

LABOV, William. Padrões Sociolinguísticos. Tradução: Marcos Bagno, Maria Marta Pereira Scherre, Caroline Rodrigues Cardoso. São Paulo: Parábola Editorial, 2008.

LABOV, William. The Social Stratification of English in New York City. Cambridge: Cambridge University Press, 2006 [1966].

LABOV, William. Where does the linguistic variable stop? A response to Beatriz Lavandera. Sociolinguistic Working Papers, n. 44, p. 1-16, 1978.

LEMLE, Miriam; NARO, Anthony J. Competências básicas do português. Relatório final de pesquisa apresentado às instituições patrocinadoras - Fundação Mobral e Fundação Ford. Rio de Janeiro, 1977.

LUCCHESI, Dante. Ciência ou dogma? O caso do livro do MEC e o ensino de língua portuguesa no Brasil. Revista Letras, n. 83, v.1, p. 83-112, 2011.

MENDES, Ronald Beline; OUSHIRO, Livia. O paulistano no mapa sociolinguístico brasileiro. Alfa, n. 56, v. 3, p.973-1001, 2012.

MEYERHOFF, Miriam. Methods, innovations and extensions: Reflections on half a century of methodology in social dialectology. Journal of Sociolinguistics, v. 20, n. 4, p. 431-452, 2016.

OLIVEIRA, Jose Luiz. As origens do MOBRAL (Dissertação de Mestrado). Instituto de Estudos Avançados em Educação. Fundação Getúlio Vargas, 1989.

RAMOS, Heloísa. Por uma vida melhor: Coleção Viver e Aprender. São Paulo: Editora Global, 2011.

RICKFORD, John R. Labov's contributions to the study of African American Vernacular English: Pursuing linguistic and social equity. Journal of Sociolinguistics, v. 20, n. 4, p. 561-580, 2016.

RODRIGUES, Angela Cecília de Souza. Fotografia sociolinguística do português do Brasil: o português popular em São Paulo. In: CASTILHO, Ataliba Teixeira de (Ed.). História do português paulista. Campinas: Instituto de Estudos da Linguagem/UNICAMP, 2009, p.151-158.

SALOMÃO, Ana Cristina Biondo. Variação e Mudança Linguística: panorama e perspectivas da sociolinguística variacionista no Brasil. Fórum Linguístico, v. 8, n. 2, p. 187-207, 2011.

SAVIANI, Dermeval. História das ideias pedagógicas no Brasil. São Paulo: Autores Associados, 2008.

SCHERRE, Maria Marta Pereira. Verdadeiro respeito pela fala da outro: realidade possível? Revista Letra 8, v.1, p. 51-62, 2013.

SCHERRE, Maria Marta Pereira; RONCARATI, Claudia. Programa de estudos sobre o uso da língua (PEUL): origens e trajetórias. In: VOTRE, Sebastião; RONCARATI, Claudia (ed.). Anthony Julius Naro e a linguística no Brasil: uma homenagem acadêmica. Rio de Janeiro: 7Letras, 2008, p. 37-49.

SOARES, Magda. Linguagem e escola: uma perspectiva social. São Paulo: Ática, 1994.

TURRA, Cleusa; VENTURI, Gustavo. Racismo cordial. São Paulo: Ática, 1995.

VOTRE, Sebastião; RONCARATI, Claudia; NASCIMENTO, Rebeca. Entrevista com Anthony Julius Naro. In: VOTRE, Sebastião; RONCARATI, Claudia (ed.). Anthony Julius Naro e a linguística no Brasil: uma homenagem acadêmica. Rio de Janeiro: 7Letras, 2008, p.13-20. 